\title{
O DESENVOLVIMENTO DE UM PRODUTO EDUCACIONAL COMO INSTRUMENTO DE ORIENTAÇÃO DE COMBATE À EVASÃO ESCOLAR EM CURSOS TÉCNICOS SUBSEQUENTES E CONCOMITANTES
}

\author{
THE DEVELOPMENT OF AN EDUCATIONAL PRODUCT AS GUIDANCE TO \\ COMBAT SCHOLAR EVASION IN SUBSEQUENT AND CONCOMITANT \\ TECHNICAL COURSE
}

DOI: http://dx.doi.org/10.23926/RPD.2526-2149.2019.v4.n2.p775-790.id475

\section{Flávia Alves de Castro Oliveira \\ Mestra em Educação \\ Profissional e Tecnológica \\ (IF Goiano - Campus \\ Morrinhos) \\ flavia.castro@ifgoiano.edu.br}

\section{José Carlos Moreira de Souza}

Doutor em Educação (UFG)

Professor no Instituto Federal

Goiano (IF Goiano)

jose.moreira@ifgoiano.edu.br
Resumo: O presente artigo tem como objetivo apresentar o produto educacional, na forma de História em Quadrinhos (HQ), intitulada "Conversa entre amigos", desenvolvida com base nos resultados da pesquisa "Evasão escolar no ensino técnico profissionalizante: um estudo de caso no Instituto Federal Goiano - Campus Ceres". A referida pesquisa foi pautada na análise dos fatores determinantes para a ocorrência da evasão escolar no Curso Técnico em Informática Subsequente/Concomitante noturno do Instituto Federal Goiano - Campus Ceres e na percepção de discentes, docentes e equipe pedagógica acerca desse fenômeno. $\mathrm{Na}$ construção do material aqui apresentado, foram observados aspectos relativos ao desenvolvimento de produtos educacionais, estabelecendo algumas unidades de sentido entre o problema da evasão escolar na Educação Profissional e Tecnológica (EPT), a História em Quadrinhos e o mundo do trabalho. Como resultados, destaca-se a disponibilização da HQ em plataforma digital, com a possibilidade de espelhar outras práticas, incentivar o desenvolvimento de ações que busquem reduzir os índices de evasão no curso pesquisado, além de contribuir para que jovens e adultos que ingressam a EPT não interrompam os percursos formativos ao longo da trajetória escolar e, como cidadãos que vivem do trabalho, possam também dar prosseguimento nos estudos.

Palavras-chave: Evasão Escolar; Mundo do Trabalho; Produto Educacional.

\begin{abstract}
The present article aims to present an educational product in comic books, titled "Conversation between friend", developed based on the results of the research "Scholar evasion in professionalizing technical education: a case study at the Federal Goiano Institute - Campus Ceres". The referred research was based on the analysis of determinant factors to the occurrence of the evasion from the Technical Course in Subsequent / Concomitant Informatics nocturnal of the Goiano Federal Institute Campus Ceres and in the perception of the students, professors and pedagogic team of these phenomena. It was observed in the development of the presented material, aspects related to the development of educational products, establishing some units of meaning among the Professional and Technological Education (PTE), the comic books and the world of work. As results, it can be emphasized that the comic books are available in a digital platform, with the possibility of mirroring other practices, encouraging the development of actions that seek to reduce the evasion indexes in the researched course and contributing to the teenagers and adults that starts PTE do not stop the training paths during the scholar journey and to those who live of the job, proceed the studies.
\end{abstract} Keywords: Scholar Evasion; Word of Work. Educacional Product. 


\section{INTRODUÇÃO}

Este artigo tem como objetivo apresentar o produto educacional, na forma de História em Quadrinhos (HQ), intitulada "Conversa entre amigos", desenvolvida com base nos resultados da pesquisa "Evasão escolar no ensino técnico profissionalizante: um estudo de caso no Instituto Federal Goiano - Campus Ceres".

Inicialmente, realizou-se um levantamento teórico/conceitual acerca do fenômeno da evasão escolar na Educação Profissional e Tecnológica e, por meio de resultados da pesquisa, foi realizada uma reflexão dos motivos da evasão escolar no Curso Técnico em Informática Subsequente/Concomitante noturno do Instituto Federal Goiano - Campus Ceres. Foram apresentados ainda, os procedimentos metodológicos observados na elaboração da HQ, baseado em autores como Kaplun (2003), Amiel (2014) e Leite (2018), com a proposta de trazer, de forma mais criativa, o diálogo e o conhecimento de fatores institucionais que foram causas da evasão escolar no curso pesquisado.

Por último, foi realizada uma análise do produto educacional, assim como também foram apresentadas as ações político-pedagógicas sugeridas pela HQ "Conversa entre amigos", que podem contribuir para a redução dos índices de evasão escolar no curso e modalidade pesquisados. Mesmo diante das dificuldades inerentes à compreensão das razões da evasão escolar, permanece o desafio de desenvolver cada vez mais ações que contribuam para a não interrupção dos percursos formativos de discentes e para o desenvolvimento de cidadãos inseridos no mundo do trabalho e também estudantes que queiram e possam dar prosseguimento nos estudos.

\section{REFERENCIAL TEÓRICO}

\subsection{Os InSTITUTOS FEDERAIS DE EDUCAÇÃO E O FENÔMENO DA EVASÃO ESCOLAR}

A institucionalização da Rede Federal de Educação Profissional, Científica e Tecnológica, por meio da Lei $n^{\circ}$ 11.892/2008, determinou a criação dos Institutos Federais de Educação, Ciência e Tecnologia (IF's) e, como resultado da referida Lei, houve a expansão da Rede Federal de Educação Profissional e Tecnológica no país. Consequentemente, houve a ampliação da oferta da Educação Profissional em suas diferentes modalidades (BRASIL, 2008).

Pondera-se ser significativo e importante o crescimento da Educação Profissional no Brasil, pois, as instituições pertencentes a essa rede, por meio de seus cursos nas diferentes modalidades de ensino, tem propiciado oportunidades inerentes à formação profissional, à formação cidadã e à inserção de diversos jovens e adultos no mundo do trabalho. 
Em relação a esse crescimento da Educação Profissional denotado pela criação dos IF's, Dore e Sales (2017) afirmam que a ampliação das oportunidades de formação profissional e tecnológica democratizou o acesso à educação no país e aumentou o número de vagas oferecidas por essas instituições, porém, ao mesmo tempo, emergiu o problema da permanência dos estudantes nas escolas, aumentando significativamente o número de indivíduos que passaram a abandonar os estudos.

Nesse sentido, verifica-se no contexto educacional brasileiro, especialmente no ensino técnico profissionalizante, apesar do aumento do número de vagas e das políticas públicas e legislações buscarem garantir o acesso à escola e a permanência do estudante nas instituições de ensino, o sistema educacional brasileiro ainda enfrenta vários desafios, inclusive o problema da evasão escolar.

No caso da Rede Federal de Educação Profissional, Científica e Tecnológica, o problema da permanência do estudante na escola e a sua evasão do sistema escolar, se tornou mais evidente a partir dos dados levantados pelo Tribunal de Contas da União (TCU), em 2012, por intermédio de auditoria realizada para caracterizar a evasão escolar nas diferentes modalidades de cursos da Rede, com ênfase nos Institutos Federais de Educação (IF's).

A partir do relatório oriundo dessa auditoria, por meio do Acórdão 506/2013, o TCU recomendou que a Secretaria de Educação Profissional e Tecnológica (SETEC), juntamente com os IF's, desenvolvesse um plano para a superação das elevadas taxas de evasão na Rede Federal de Educação Profissional. Dessa forma, foi instituído, pela SETEC, um Grupo de Trabalho, com o objetivo de estudar e propor soluções para a evasão escolar nos cursos e modalidades de ensino da referida rede. Assim, no ano de 2014, foi elaborado e publicado pela SETEC, o "Documento orientador para a superação da evasão e retenção na Rede Federal", que, após direcionar diferentes estudos, trouxe subsídios e propôs a elaboração de um plano estratégico de intervenção e monitoramento, com a intenção de subsidiar cada instituição da Rede Federal a elaborar e desenvolver o seu próprio plano estratégico (BRASIL, 2014).

É importante mencionar ainda o Programa de Acolhimento, Permanência e Êxito (PAPE), criado em 2016 pelo Ministério da Educação em parceria com o Ministério da Saúde e o Ministério do Desenvolvimento Social e Combate à Fome, que teve como intuito fomentar diálogos em âmbito federal, estadual e municipal sobre as razões do abandono escolar pelos estudantes. Baseado no Censo Escolar de 2015, por meio de profissionais ligados à educação, saúde e assistência social, em todo o território nacional, o programa buscou a realização de 
visitas às famílias de crianças e adolescentes em idade escolar para incentivar a matrículas e a reinserção desses nas instituições de ensino.

Em relação ao Instituto Federal Goiano (IF Goiano) e seus campi, encontra-se em andamento, o Plano Estratégico de Permanência e Êxito (PEPE), desenvolvido pela PróReitoria de Ensino e Pró-Reitoria de Extensão do IF Goiano junto aos 12 campi do instituto. Trata-se de um projeto, no âmbito do IF Goiano, que contempla o diagnóstico dos principais fatores de evasão e retenção dos estudantes da Educação Básica Profissional e Superior, que busca definir ações pedagógicas e administrativas que visam monitorar e, consequentemente, reduzir as taxas de evasão e retenção nos próximos anos para os diferentes cursos e modalidades ofertados.

Nesse sentido, a evasão escolar é um fenômeno complexo e um problema educacional que tem sido discutido no âmbito escolar, por educadores e pesquisadores. Todas essas iniciativas congraçam-se à própria Lei de Diretrizes e Bases da Educação n. o 9.394/1996 (LDB n ${ }^{\circ}$ 9394/1996), que em seu art. $3^{\circ}$, inciso I, pontua que o ensino deverá ser ministrado com base na igualdade de condições para o acesso e a permanência na escola (BRASIL, 1996).

No entanto, para garantir assim o acesso e a permanência do discente, é necessário que se compreenda o fenômeno educacional da evasão escolar. Porém, entender e solucionar o problema da evasão escolar são tarefas complexas, visto que esse fenômeno é multifacetado, ou seja, não há apenas uma única causa que seja definidora do motivo do aluno abandonar a escola. Dore e Lüscher (2011) pontuam que, na discussão de contexto mais amplo, deve-se levar em conta que a evasão escolar não tem um motivo específico, pois é um fenômeno complexo, que engloba fatores individuais e institucionais.

Ressalta-se que, em razão do conceito de evasão escolar ser discutido e controverso, a pesquisa realizada considerou a evasão escolar, baseando-se na concepção trazida por Dore (2013), que a conceitua como a saída definitiva da escola, ou seja, quando o percurso escolar é interrompido pelo aluno que, por diferentes motivos, deixa de frequentar as aulas e o curso iniciado, interrompendo o percurso formativo naquele grau acadêmico que havia proposto, não voltando à instituição para concluí-lo.

Assim, para alcançar a implementação de estratégias que busquem a permanência do estudante na escola, a pesquisa baseou-se na importância de compreender os fatores determinantes da ocorrência desse fenômeno, levando em consideração tanto os fatores de ordem individual/pessoal de cada um dos discentes, bem como possíveis fatores relativos à 
instituição escolar, que levam à saída do aluno da instituição. Com o intuito de explicar esse fenômeno, Dore e Lüscher, afirmam que:

Do vasto e intricado conjunto de circunstâncias individuais, institucionais e e sociais presentes na análise da evasão, destaca-se a explicação de que a evasão é um processo complexo, dinâmico e cumulativo de desengajamento do estudante da vida da escola. A saída do estudante da escola é apenas o estágio final desse processo (DORE; LÜSCHER, 2011, p.777).

Quaisquer que sejam os motivos, a compreensão dos fatores determinantes da evasão escolar e a definição de estratégias específicas para as diversas situações que envolvem o abandono escolar pelo discente podem ser importantes para se alcançar e elevar os índices de permanência do estudante na instituição, assim como, a Educação Profissional pode ser a oportunidade de jovens e adultos despertarem o interesse pela elevação da escolaridade.

\section{Procedimentos Metodológicos}

Tendo como base a Educação Profissional e a ocorrência da evasão escolar por múltiplas razões, o estudo e a HQ desenvolvida tiveram enfoque na evasão escolar, no Curso Técnico em Informática Subsequente/Concomitante do Instituto Federal Goiano - Campus Ceres, no período noturno, na modalidade presencial e no recorte temporal que compreendeu os anos de 2015 a 2018.

Referida pesquisa utilizou-se de uma abordagem metodológica quanti-qualitativa e para coleta de dados apoiou-se nos seguintes instrumentos: pesquisa bibliográfica e pesquisa documental para a construção da fundamentação teórica e levantamento de informações a respeito do curso pesquisado; pesquisa de campo, por meio de questionários semiestruturados, com questões fechadas e abertas, aplicados a dezessete (17) discentes evadidos, doze (12) docentes (dentre eles dois coordenadores de curso) e três (03) membros da equipe pedagógica, buscando identificar, dentre outros aspectos, os principais motivos da evasão escolar no curso em questão. Ressalta-se aqui, que o projeto de pesquisa e os questionários aplicados foram previamente submetidos ao Comitê de Ética em Pesquisa do Instituto Federal Goiano, visando à verificação dos aspectos éticos legais e a proteção necessária ao pesquisador e aos participantes envolvidos no estudo.

Considerando os diversos fatores que são intervenientes e motivadores da ocorrência da evasão escolar e por se tratar de um fenômeno complexo, a proposta não é solucionar o problema, mas sugerir ações que contribuam para aumentar os índices de permanência dos estudantes na escola, bem como valorizar e consolidar a identidade do Curso Técnico em Informática Subsequente/Concomitante pesquisado. 
Nesse contexto, como fruto da pesquisa realizada, a proposta foi o desenvolvimento de um produto educacional, correlacionados à pesquisa desenvolvida, que pudesse contribuir para a EPT e a instituição pesquisada. Inicialmente, pensou-se em um material que se enquadrasse na categoria material textual, na espécie de cartilha. Porém, ao analisar os aspectos relativos à sustentabilidade ambiental e à criação de um produto educacional que despertasse mais a atenção dos leitores, possibilitasse uma maior divulgação dos resultados da pesquisa e não se tornasse apenas uma cartilha engavetada, trabalhou-se o desenvolvimento de uma História em Quadrinhos.

Para dar continuidade ao trabalho de construção desse produto educacional, tomou-se por base a ideia de um Recurso Educacional Aberto (REA), que, como afirma Amiel (2014), recursos educacionais abertos podem colaborar, em muito, para a democratização do acesso ao conhecimento. A HQ foi organizada como um REA, com uma linguagem mais aproximada da rotina dos jovens e com a utilização de imagens e textos, que podem alcançar mais facilmente os alunos e docentes do curso. Leite (2018), quanto aos Produtos Educacionais desenvolvidos, reforça que:

Tais produtos ou processos precisam ser aplicados em condições reais de sala de aula ou de espaços não formais ou informais de ensino e podem assumir as seguintes formas: mídias educacionais; protótipos educacionais e materiais para atividades experimentais; propostas de ensino; material textual; materiais interativos; atividades de extensão e desenvolvimento de aplicativos. (LEITE, 2018, p. 331).

Segue exemplo da tela inicial da HQ:

Figura 1 - Tela inicial da História em Quadrinhos

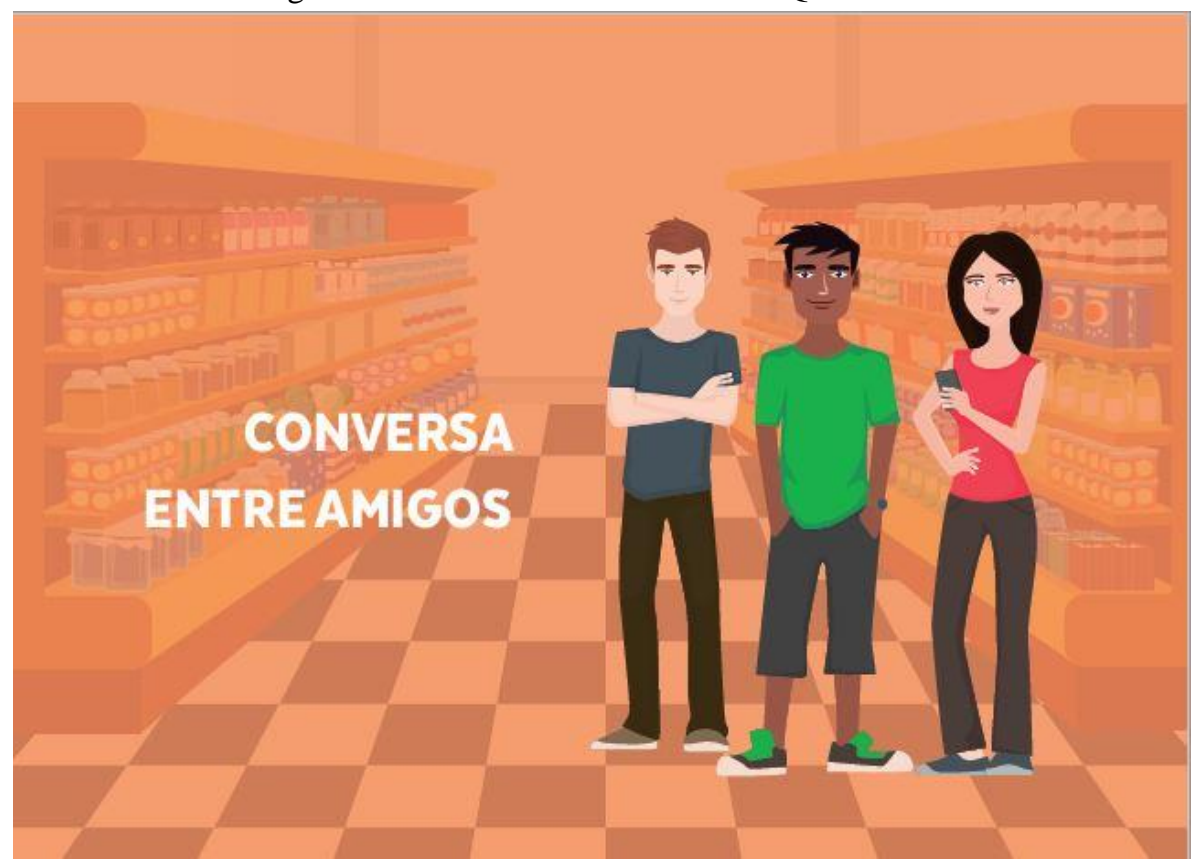

Fonte: Elaboração própria. 
Para confecção desse material valeu-se da elaboração de um roteiro prévio e também da observação de alguns aspectos importantes para o desenvolvimento de um produto educacional, quais sejam: bases conceituais da Educação Profissional e Tecnológica, avaliação e validação do produto educacional e direitos autorais.

Em relação ao contexto da EPT, para observação do fenômeno da evasão escolar, especialmente na modalidade subsequente e concomitante, levou-se em consideração a característica de jovens e adultos trabalhadores, reforçando-se dimensões importantes da Educação Profissional, como a reflexão do trabalho como princípio educativo, a inserção no mundo do trabalho e a formação de cidadãos emancipados e não alienados, com capacidade de transformação social.

Devido ao fato de serem alunos na condição de trabalhador, ou seja, de cidadãos que vivem do trabalho e que, em sua maioria, apresentam dificuldades de conciliar trabalho e estudo, o quadrinho pontuou aspectos importantes no tocante à formação de cidadãos capacitados para compreender o mundo do trabalho. A HQ "Conversa entre amigos" traz a possibilidade de proporcionar aos jovens, em geral, filhos de trabalhadores, uma direção para o início de suas carreiras profissionais, numa transição não alienada para o mundo do trabalho, bem como a possibilidade de prosseguir nos estudos no ensino superior.

Daí a percepção de se preparar para o mundo do trabalho, quando "o trabalho não se reduz à atividade laborativa ou emprego, mas à produção de todas as dimensões da vida humana" (FRIGOTTO, 2012, p. 58-59). Trabalho como princípio educativo é um das dimensões que norteiam a superação da dualidade e a formação de cidadãos capacitados para compreender o mundo do trabalho, a realidade social, econômica, política e cultural que estão inseridos.

Outra questão que foi pontuada e trabalhada no produto educacional desenvolvido é a pesquisa como princípio educativo. Buscando compreender a importância de estabelecer a unidade entre teoria e prática, o quadrinho por meio de uma linguagem mais despojada, reforça a necessidade do desenvolvimento de projetos e pesquisas científicas com engajamento da comunidade estudantil. A pesquisa como princípio educativo contribui para a construção da autonomia intelectual do educando, desperta inquietude, vontade e interesse por parte dos discentes (MOURA, 2007), e, dessa forma, contribui para a não interrupção dos percursos formativos por parte dos estudantes. 
Quanto aos aspectos relacionados à avaliação e validação do produto educacional, ao desenvolver a HQ observou-se os três eixos pedagógicos trazidos Kaplún (2003), descrevendose a seguir de que maneira esses eixos contribuíram para elaboração do material:

- Eixo conceitual - utilizando-se de estudos e contribuições de diversos autores no campo da evasão escolar, especialmente na Educação Profissional e Tecnológica, conheceramse debates, temas principais e secundários envolvidos no fenômeno multifacetado da evasão.

- Eixo pedagógico - Partindo das respostas dos alunos evadidos, docentes e equipe pedagógica, elaborou-se um roteiro, com uma linguagem simples, de modo que as pessoas não se sintam ignorantes ao ler o material produzido, mas que possam questionar, descontruir concepções iniciais, dialogar para que, a partir da história contada, possam repensar e estabelecer ações concretas que contribuam para redução das taxas de evasão no curso.

- Eixo comunicacional - o quadrinho foi desenvolvido de forma criativa, que chame atenção e que atraia mais leitores, para não ser apenas uma cartilha engavetada.

A História em Quadrinhos "Conversa entre amigos" foi aplicada junto aos alunos, docentes e equipe pedagógica do Curso Técnico em Informática Subsequente/Concomitante noturno do IF Goiano - Campus Ceres e encontra-se, na íntegra, disponível em repositório digital, por meio do link https://repositorio.ifgoiano.edu.br/handle/prefix/587.

Após essa etapa, para avaliação e validação do quadrinho desenvolvido, observou-se a proposta trazida por Leite (2018), por meio de um guia de perguntas, composto de cinco questões fechadas e uma aberta, tendo como agentes validadores membros da equipe pedagógica, docentes e discentes do curso, para observação de aspectos como atração, mudança de ação, estética, estilo de escrita, conteúdo e propostas trazidas pelo material didático apresentado.

Ainda em relação à divulgação da $\mathrm{HQ}$, para se concretizar a proposta de compartilhamento da História em Quadrinhos, concorda-se com Amiel (2014), quando o autor traz apontamentos importantes para desenvolvimento de um Recurso Educacional Aberto e relata que um agregado de imagens e textos digitais, disponibilizados abertamente, podem fomentar a produção e a disseminação de conteúdo educacional, com liberdade de uso e reúso. $\mathrm{O}$ autor aborda ainda a questão do compartilhamento como forma de propiciar a oportunidade para que os outros utilizem, relacionem e criem outros recursos educacionais abertos.

A partir das pontuações trazidas por Amiel (2014), apreendem-se algumas vantagens da proposta de compartilhamento da $\mathrm{HQ}$ em repositório digital, como: a questão da sustentabilidade, por tratar-se de recurso digital e não impresso; a questão do acesso, pois pode 
ser lida por várias pessoas ao mesmo tempo e com mais facilidade de acesso; as possibilidades de utilização desse material. Tudo isso visando à divulgação da História em Quadrinhos como possibilidade de difundir ainda mais o resultado da pesquisa e espelhar outras práticas a serem desenvolvidas por pesquisadores futuros.

Por todo o exposto e em se tratando da possibilidade de uso e reúso, quando se observa direitos autorais em relação ao produto desenvolvido, a licença utilizada e que corrobora com o caráter pedagógico e educacional da HQ é a Creative Commons, pois dá maior flexibilidade e possibilita tipos de permissões e acessos diferenciados. No caso da História em Quadrinhos, foi utilizada a licença do tipo CC BY-NC-ND, que permite que os outros façam download e compartilhamento, porém, o crédito deverá ser atribuído ao autor, não podendo alterá-la ou utilizá-la para fins comerciais.

\section{Resultados encontrados: Fatores determinantes E PERCEPÇão DE Discentes, DOCENTES E EQUIPE PEDAGÓGICA}

Em relação ao curso pesquisado, a partir da análise dos dados levantados, foi observado que há um grande número de discentes que abandonaram o curso e não voltaram à instituição para sua conclusão. Segundo dados constantes da Seção de Registros Escolares, para os anos de 2015 e 2016 a quantidade de alunos evadidos ultrapassa o patamar de 50\% dos matriculados, e para os alunos matriculados nos anos de 2017 e 2018, os índices são $28 \%$ e $61,11 \%$, respectivamente.

Foi possível perceber que o Curso Técnico em Informática Subsequente/ Concomitante do IF Goiano - Campus Ceres, mesmo oportunizando o acesso ao curso por alunos que concluíram o Ensino Médio (modalidade subsequente) e alunos que ainda estejam cursando a $3^{a}$ série do Ensino Médio (modalidade concomitante), em relação aos alunos que participaram da pesquisa, todos eles ingressaram no curso na modalidade subsequente, ou seja, já haviam concluído o ensino médio e buscavam a formação profissional oferecida no curso, sendo em sua maioria homens (70,59\%) na faixa etária de 20 a 25 anos.

Na perspectiva dos motivos individuais, com causadores da evasão escolar, encontramse as condições financeiras, o nível educacional dos pais, a estrutura da família, o desinteresse pela vida escolar dos filhos, a necessidade de trabalhar do próprio aluno, as dificuldades inerentes a conciliar trabalho e estudo, dentre outros. Na perspectiva da escola, também aliado a outros fatores, que podem ser relacionados à saída do estudante, cita-se o despreparo do corpo 
docente, as práticas pedagógicas, currículos descontextualizados, poucas aulas práticas e a falta de incentivo e motivação para estudar.

Infere-se ainda dos dados analisados, que os alunos evadidos são, em sua maioria, estudantes de camadas socioeconômicas desfavorecidas, com renda familiar baixa, que concluíram o ensino médio somente em escola da rede pública e com pai e mãe com nível de escolaridade baixo. Confirma-se aqui, as pontuações trazidas por Dore (2013), de há uma tendência maior de demanda por Educação Profissional e Tecnológica por alunos de camadas socioeconômicas desfavorecidas e que têm maior chance de deixar as escolas que os alunos de classe média.

Com base nas respostas dos discentes e pautando-se nos objetivos inicialmente definidos no estudo, foi analisada a principal causa apontada pelos estudantes como determinantes para a ocorrência da evasão escolar. Infere-se da observação do Gráfico 1, que o principal motivo apontado foi a dificuldade de conciliar trabalho e estudo, com percentual de $47,06 \%$, o que corresponde a 08 dos 17 alunos evadidos pesquisados.

Gráfico 1 - Percentual de alunos em relação ao principal motivo de abandonar o curso antes da conclusão

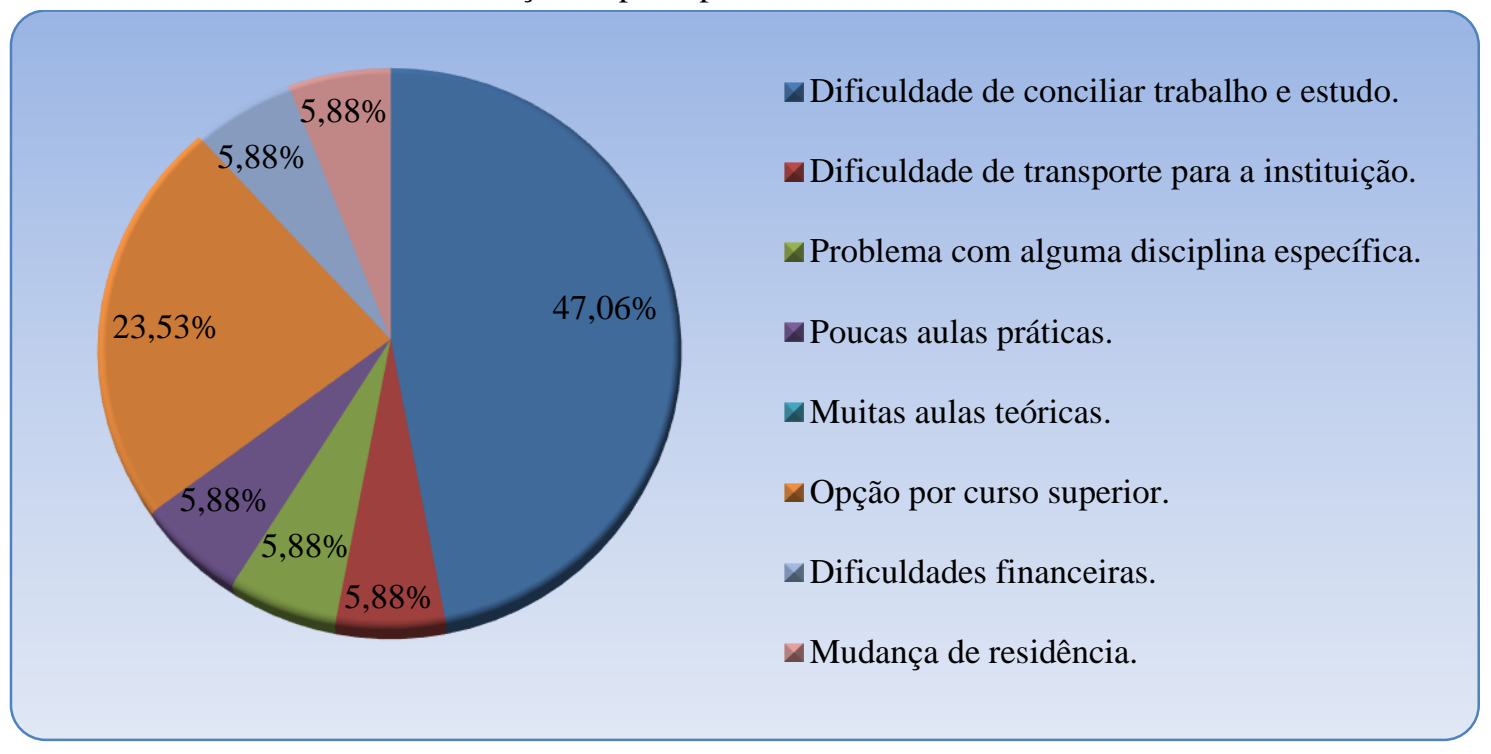

Fonte: elaboração própria, a partir dos dados da pesquisa.

Pelas declarações dos estudantes, percebeu-se que eles têm pouco tempo disponível para os estudos, o que é uma característica comum de estudantes do turno noturno e que abandonam a escola em razão das dificuldades inerentes à compatibilidade entre a vida acadêmica e as exigências do mundo do trabalho. Fritsch (2017) aponta em seus estudos que:

Alguns estudantes reconhecem que a decisão por eles tomada é importante. Sabem que quando optam por deixar os estudos isso poderá gerar posteriores consequências em suas histórias de vida e nas oportunidades que poderiam encontrar pelo caminho. 
No entanto, dão prioridade ao emprego em detrimento do estudo (FRITSCH, 2017, p. 89-90).

Dessa forma, muitos jovens e/ou adultos, que ingressam no mundo do trabalho tentam, mas não conseguem conciliar os estudos e as imposições da vida de estudante, com as necessidades inerentes à vida de trabalhador, à sobrecarga de trabalho e as atividades diárias realizadas para seu sustento próprio e da família. Assim, acabam dando prioridade ao emprego e abandonando os estudos (MAGRONE, 2017).

Porém, ao analisar outros fatores apontados pelos estudantes, foi possível identificar diferentes causas que contribuíram para abandonar o curso antes da conclusão como: opção por curso superior, dificuldade de transporte para a instituição, poucas aulas práticas, dificuldades financeiras, mudança de residência, dificuldades com disciplinas específicas da área de programação e falta de identificação com o curso e a sua área de abrangência. Confirma-se aqui a percepção trazida por autores como Dore e Lüscher (2011), Queiroz (2010) e Fritsch (2017), que, em seus estudos, pontuam que a evasão escolar é um processo complexo e que ocorre em razão de diversos fatores de ordem individual e institucional, que juntos culminam na decisão, pelo estudante, de abandonar o curso antes de sua conclusão.

Dentre as respostas dos docentes, dentre eles os coordenadores de curso, merece destaque, o fato de confirmarem que, apesar de perceberem os sinais característicos de estudantes propensos a evadir do sistema escolar, tais como faltas recorrentes, desinteresse, sono durante as aulas, pouco rendimento e desmotivação em participar das atividades desenvolvidas, muitas vezes, eles desconhecem protocolos estabelecidos pela instituição para os casos de evasão. Reforça-se aqui, as considerações de Dore e Lüscher (2011), quando observam a importância da prevenção e identificação precoce dos sinais do abandono escolar, bem como pontuam que o acompanhamento individual daqueles que estão em situação de risco de evasão, pode ser um fator chave para a conclusão do curso e o êxito escolar desse aluno.

Nesse cenário, com base na pesquisa realizada, é importante mencionar que, no âmbito do IF Goiano - Campus Ceres, impõe-se uma contradição de caráter político-pedagógico, haja vista que apesar da existência e trabalhos realizados pelo Plano Estratégico de Permanência e Êxito, há pouca discussão e enfrentamento do problema, quando observadas as ações que efetivamente têm sido implementadas em relação ao Curso Técnico em Informática Subsequente / Concomitante do IF Goiano - Campus Ceres, para incentivar a permanência do aluno na instituição. 


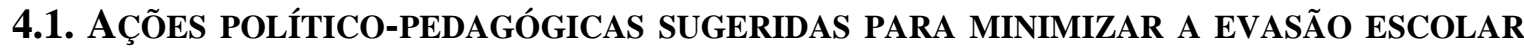 No CURSo TÉCNICO EM INFORMÁTICA SUBSEQUENTE / CONCOMITANTE, DO TURNO NOTURNO, DO IF GOIANO - CAMPUS CERES}

A elaboração da História em Quadrinhos aqui apresentada observou todos os aspectos acima descritos e procurou, por meio de uma linguagem simples e aproximada do universo juvenil, despertar uma leitura atraente às diferentes pessoas que a ela terão acesso. Para exemplificar, segue abaixo uma das telas da História em Quadrinhos produzida, que apresenta sugestões dos próprios alunos pesquisados.

Figura 2 - Tela da história em quadrinhos com sugestões dos próprios alunos

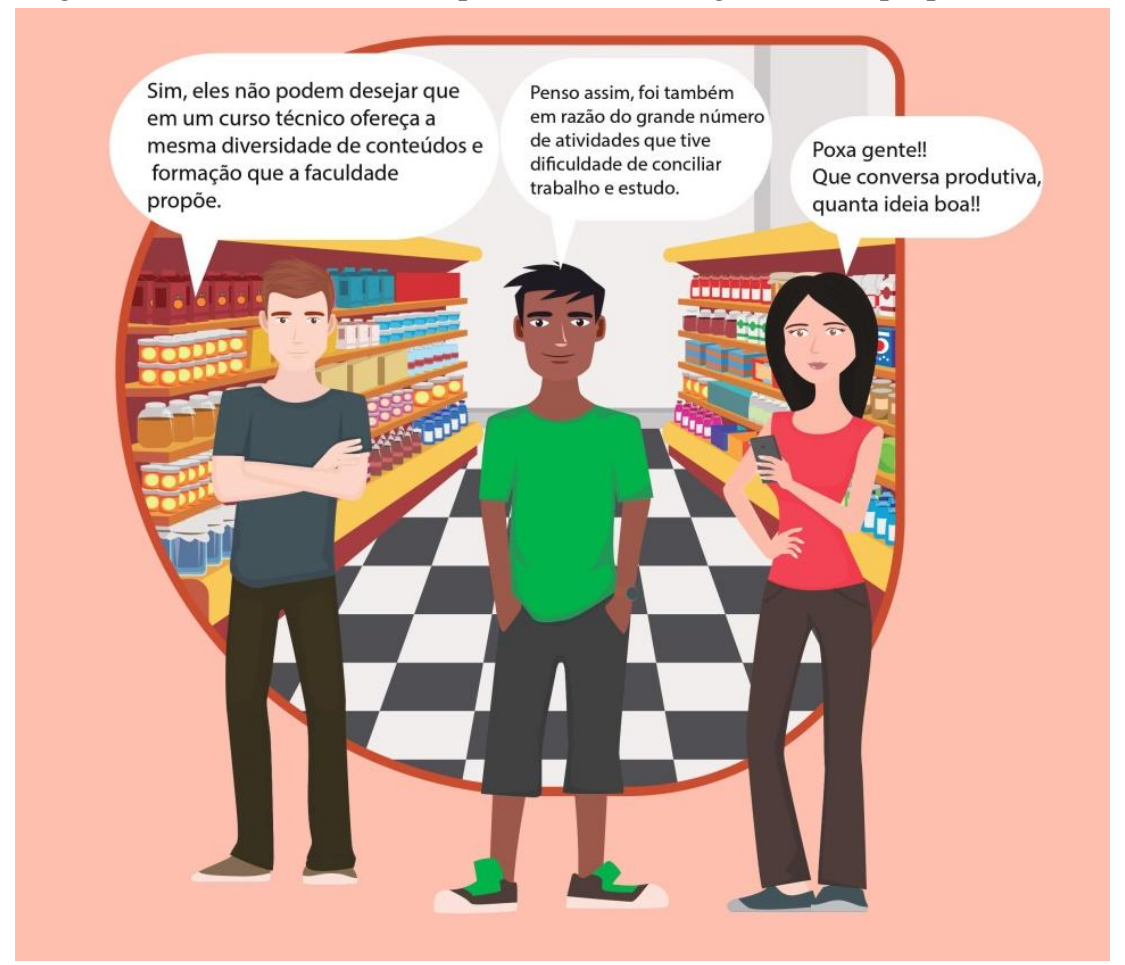

Fonte: elaboração própria a partir de sugestões dos estudantes evadidos.

A seguir, apresentam-se também as ações político-pedagógicas propostas pela HQ, que podem contribuir para redução das taxas de evasão escolar no curso em questão.

Quadro 1 - Ações político-pedagógicas sugeridas para minimizar a evasão escolar no Curso Técnico em Informática Subsequente/Concomitante, do turno noturno, do IF Goiano - Campus Ceres

\begin{tabular}{|c|l|}
\hline Fator a ser observado & \multicolumn{1}{c|}{ Ação sugerida } \\
\hline \multirow{2}{*}{$\begin{array}{c}\text { Alunos com problemas recorrentes } \\
\text { de assiduidade e pontualidade nas } \\
\text { aulas }\end{array}$} & $\begin{array}{l}\text { - Desenvolver ações que contemplem o acompanhamento individual de } \\
\text { estudantes com problemas de assiduidade e pontualidade, por meio de } \\
\text { registros, documentação de atrasos e ausências recorrentes de discentes, } \\
\text { para posterior comunicação à equipe pedagógica da instituição. } \\
\text { - Trabalhar a ideia de que a pontualidade e assiduidade são fatores } \\
\text { determinantes para o sucesso na vida acadêmica e profissional. }\end{array}$ \\
\hline
\end{tabular}




\begin{tabular}{|c|c|}
\hline & - Docentes também devem ser pontuais e assíduos. \\
\hline $\begin{array}{l}\text { Discentes com baixo rendimento } \\
\text { escolar }\end{array}$ & $\begin{array}{l}\text { - Docentes não devem adotar a postura "aqueles que não acompanham pior } \\
\text { para eles". O professor deve procurar mecanismos pedagógicos e didáticos, } \\
\text { para que os alunos possam se interessar em melhorar o rendimento escolar } \\
\text { com o devido acompanhamento e atenção por parte do docente. } \\
\text { - Buscar desenvolver mais aulas práticas. }\end{array}$ \\
\hline $\begin{array}{l}\text { Alunos com defasagem de } \\
\text { conteúdos do ensino médio e/ou } \\
\text { ensino fundamental. }\end{array}$ & $\begin{array}{l}\text { - Retomar conteúdos de base, pois, se trata de um público-alvo em que } \\
\text { alguns possuem defasagens de séries anteriores. Dessa forma, a instituição } \\
\text { irá acudir os alunos com dificuldades de aprendizagem, ao invés de excluí- } \\
\text { los do sistema. }\end{array}$ \\
\hline $\begin{array}{l}\text { Dificuldade de transporte para a } \\
\text { instituição }\end{array}$ & $\begin{array}{l}\text { - Devido à distância entre o IF Goiano - Campus Ceres e a cidade sugere- } \\
\text { se uma melhor divulgação de informações referentes aos programas de } \\
\text { assistência estudantil existentes na instituição, especialmente para os cursos } \\
\text { da modalidade subsequente e concomitante, que tem pouco conhecimento } \\
\text { da possiblidade de concorrerem aos benefícios do auxílio transporte. } \\
\text { - Ampliar a busca de parcerias junto às prefeituras municipais no sentido de } \\
\text { auxiliar no transporte de alunos para a instituição. }\end{array}$ \\
\hline $\begin{array}{l}\text { Estudantes com dificuldade de } \\
\text { aprendizagem em disciplinas } \\
\text { específicas }\end{array}$ & $\begin{array}{l}\text { - Buscar parcerias para aumentar as aulas práticas. } \\
\text { - Buscar a ampliação do Programa de Monitoria desenvolvido na instituição, } \\
\text { para que alcance também os cursos subsequentes e, após, incentivar a } \\
\text { participação dos alunos no referido programa, para que haja uma efetiva } \\
\text { recuperação paralela de conteúdos e componentes curriculares. } \\
\text { - Incentivar o desenvolvimento de grupos de estudo a serem criados pelos } \\
\text { próprios estudantes. } \\
\text { - Desenvolver atividades que levem os discentes a perceber a importância } \\
\text { de estabelecer uma rotina diária para estudos. }\end{array}$ \\
\hline $\begin{array}{l}\text { Discentes com dificuldade de } \\
\text { conciliar a vida acadêmica e as } \\
\text { exigências da vida de trabalhador }\end{array}$ & $\begin{array}{l}\text { - Desenvolver projetos de pesquisa e extensão com envolvimento da } \\
\text { comunidade estudantil. } \\
\text { - Priorizar atividades desenvolvidas no horário de aula, diminuindo assim a } \\
\text { sobrecarga de trabalho extraclasse, limitando esses trabalhos de acordo com } \\
\text { a realidade dos alunos. } \\
\text { - Professores devem estar atentos ao excesso de cobrança e ao excesso de } \\
\text { avaliações. } \\
\text { - Desenvolver, nos alunos, a percepção da importância dos estudos e da } \\
\text { qualificação para a inserção e a permanência no mundo do trabalho. } \\
\text { - Rever as práticas de ensino, com metodologia diversificada, que incentive } \\
\text { os alunos a continuar os estudos, mesmo diante das dificuldades } \\
\text { enfrentadas. } \\
\text { - Realizar o diálogo com as empresas da região, visando permitir uma } \\
\text { melhor conciliação entre os horários de trabalho e os horários do curso e } \\
\text { principalmente com horários de estudo. } \\
\text { - Divulgar, durante o curso, as possibilidades de atuação profissional e, ao } \\
\text { mesmo tempo, a possibilidade de dar sequência nos estudos em nível } \\
\text { superior na mesma área, inclusive na própria instituição. }\end{array}$ \\
\hline $\begin{array}{c}\text { Estudantes desmotivados e } \\
\text { desinteressados com o próprio } \\
\text { curso }\end{array}$ & $\begin{array}{l}\text { - Docentes devem estar atentos e registrar as possíveis razões do } \\
\text { desinteresse e da desmotivação do estudante do curso. } \\
\text { - Melhor divulgação do curso, do perfil do aluno egresso e das } \\
\text { oportunidades de atuação profissional. }\end{array}$ \\
\hline
\end{tabular}




\begin{tabular}{|c|c|}
\hline & $\begin{array}{l}\text { - Incentivar o desenvolvimento de programas que fortaleçam o ambiente } \\
\text { institucional, desenvolvendo práticas acolhedoras, colaborativas, que } \\
\text { estimulem a permanência do aluno na instituição, a aprendizagem e a } \\
\text { formação cidadã. } \\
\text { - Buscar parcerias, junto às empresas da região, para implementação de } \\
\text { oportunidades de estágio, para o desenvolvimento projetos de extensão e } \\
\text { visitas técnicas junto a essas empresas, bem como oportunidades de } \\
\text { trabalho, articulando assim, a absorção de alunos atuais e de egressos no } \\
\text { mundo do trabalho. } \\
\text { - Reconhecimento dos saberes dos alunos que já tem conhecimento e atuam } \\
\text { na área, realizando a avaliação e a certificação profissional desses } \\
\text { estudantes. }\end{array}$ \\
\hline $\begin{array}{l}\text { Dificuldade de acompanhamento } \\
\text { individual por parte da instituição e } \\
\text { dos professores }\end{array}$ & $\begin{array}{l}\text { - Realizar reuniões periódicas com os próprios alunos ou representantes de } \\
\text { turmas para identificar sugestões de melhoria, e dessa forma ampliar a } \\
\text { participação dos estudantes no comprometimento e no desenvolvimento de } \\
\text { ações que possam consolidar a identidade do curso. }\end{array}$ \\
\hline Para casos concretos de evasão & $\begin{array}{l}\text { - Procurar o aluno e informar ao estudante evadido a possibilidade de } \\
\text { retorno à instituição para conclusão do curso e continuidade dos estudos. }\end{array}$ \\
\hline
\end{tabular}

Fonte: Elaboração própria a partir dos resultados da pesquisa.

\section{CONSIDERAÇÕES FINAIS}

A partir das reflexões trazidas ao longo desse artigo e da pesquisa realizada, amparandose na preocupação de apreender os fatores que motivaram a evasão escolar no curso pesquisado, a apresentação de um produto educacional na forma de História em Quadrinhos, sua disponibilização digital e consequente divulgação, é fruto da proposta de difundir os resultados da pesquisa, e, de maneira lúdica, espelhar outras práticas, provocar diálogo, inquietação e mudança de ação em relação ao complexo problema da evasão escolar no contexto da Educação Profissional e Tecnológica.

Assim, na análise dos resultados obtidos na pesquisa, em relação à dificuldade de conciliar trabalho e estudo e também em relação aos demais motivos apontados pelos próprios estudantes como fatores determinantes para a ocorrência do abandono escolar pelo discente, por meio do produto educacional aqui apresentado, busca-se difundir a sugestão de ações político-pedagógicas que contribuam, tanto para a redução dos índices de evasão escolar no Curso Técnico em Informática Subsequente / Concomitante, do turno noturno, do IF Goiano Campus Ceres quanto para a consequente permanência de estudantes nos demais cursos oferecidos pela instituição e nas diferentes modalidades de ensino, quando se trata da Educação Profissional e Tecnológica.

Por todas essas considerações, fica o desafio de desenvolver cada vez mais ações que busquem o combate à evasão escolar, com a consequente valorização e construção da identidade do curso pesquisado. Tais ações podem favorecer a permanência e o sucesso na vida de 
estudantes que buscam a formação profissional como uma alternativa possível para que os que vivem do trabalho e também para que, se assim desejarem, possam dar prosseguimento nos estudos em nível superior.

\section{REFERÊNCIAS}

AMIEL, Tel. Recursos Educacionais Abertos: uma análise a partir do livro didático de história. In: Revista História Hoje. São Paulo, v.3, n.5, p. 189-205, 2014.

BRASIL. Lei no 11.892, de 29 de dezembro de 2008. Institui a Rede Federal de Educação Profissional, Científica e Tecnológica, cria os Institutos Federais de Educação, Ciência e Tecnologia, e dá outras providências. Brasília, DF: Presidência da República, [2008]. Disponível em: http://www.planalto.gov.br/ccivil_03/_ato2007-2010/2008/lei/l11892.htm. Acesso em 12 out. 2017.

BRASIL. Lei $\mathrm{n}^{0}$ 9.394, de 20 de dezembro de 1996. Estabelece as diretrizes e bases da educação nacional. Brasília, DF: Presidência da República, [1996]. Disponível em: http://www.planalto.gov.br/ccivil_03/leis/L9394.htm . Acesso em 20 nov. 2018.

BRASIL. Relatório de auditoria operacional em ações da Rede Federal de Educação Profissional, Científica e Tecnológica. Brasília, DF: junho de 2012. TCU/Seprog. Disponível em: https://portal.tcu.gov.br/lumis/portal/file/fileDownload.jsp?inline=1\&fileId=8A8182A14D927 92C014D92847E5F3E97. Acesso em 12 mar. 2018.

BRASIL. Documento Orientador para a Superação da Evasão e Retenção na Rede Federal de Educação Profissional, Científica e Tecnológica - MEC-SETEC. Brasília, DF: 2014. Disponível em: http://r1.ufrrj.br/ctur/wp-content/uploads/2017/03/DocumentoOrientador-SETEC.pdf. Acesso em 22 abr. 2018.

DORE, Rosemary. Evasão e repetência na rede federal de educação profissional. Programa Observatório da Educação/CAPES/INEP/Reditec/Maceió-AL, set. 2013. Disponível em: http://www.reditec.ifal.edu.br/arquivos-1/apresentacoes/dia-04-09. Acesso em 08 mar. 2019.

DORE, Rosemary; LÜSCHER, Ana Zuleima. Permanência e evasão na educação técnica de nível médio em Minas Gerais. Cadernos de pesquisa, v. 41, n. 144, p. 772-789, set./dez. 2011.

DORE, Rosemary; SALES, Paula Elisabeth Nogueira. Origem social dos estudantes como contraponto à evasão e à permanência nos cursos técnicos da Rede Federal de Educação Profissional. In: DORE, Rosemary et al (Orgs.). Educação Profissional e Evasão Escolar: contextos e perspectivas. Belo Horizonte: RIMEPES, 2017.

FRIGOTTO, Gaudêncio. Concepções e mudanças no mundo do trabalho e o ensino médio. In: FRIGOTTO, Gaudêncio; CIAVATTA, Maria; RAMOS, Marise (Orgs.). Ensino Médio Integrado: concepção e contradições. 3. ed. São Paulo: Cortez, 2012. 
FRITSCH, Rosangela. Evasão escolar, mundo da escola e o mercado de trabalho: o que dizem jovens do Ensino Médio de escolas públicas. In: DORE, Rosemary et al (Orgs.). Educação Profissional e Evasão Escolar: contextos e perspectivas. Belo Horizonte: RIMEPES, 2017.

KAPLÚN, Gabriel. Material educativo: a experiência de aprendizado. Comunicação \& Educação. São Paulo, v. 27, p. 46-60, mai./ago. 2003.

LEITE, Priscila de Souza Chisté. Produtos educacionais em mestrados profissionais na área de ensino: uma proposta de avaliação coletiva de materiais educativos. In: CONGRESSO IBERO-AMERICANO EM INVESTIGAÇÃO QUALITATIVA, 7., 2018, Fortaleza. Anais[...] Fortaleza: UNIFOR, 2018. Disponível em: https://proceedings.ciaiq.org/index.php/ciaiq2018/article/view/1656/1609. Acesso em 23 nov. 2018.

MAGRONE, Eduardo. “O que você vais ser quando crescer?” Algumas notas sobre a transição escola-trabalho e a liberdade filisteia. In: DORE, Rosemary et al (Org.). Educação Profissional e Evasão Escolar: contextos e perspectivas. Belo Horizonte: RIMEPES, 2017.

MOURA, Dante Henrique. Educação básica e educação profissional e tecnológica: dualidade histórica e perspectiva de integração. Revista Holos, Natal, v.2, p.1-27, 2007. Disponível em: http://www2.ifrn.edu.br/ojs/index.php/HOLOS/article/viewFile/11/110. Acesso em 03 nov. 2018.

QUEIROZ, Lucineide Domingos. Um estudo sobre a evasão escolar: para se pensar na inclusão escolar. 2010. Disponível em:

www.25reuniao.anped.org.br/lucileidedomingosqueirozt13.rtf. Acesso em 18 abr. 2018.

Recebido em: 03 de junho de 2019.

Aprovado em: 27 de setembro de 2019. 